\title{
Commentary on Lahdelma and Eerola
}

\author{
MICHAEL SPITZER \\ Department of Music, University of Liverpool
}

\begin{abstract}
This commentary offers a critique of the idea that nostalgia can be conveyed by a single chord - a major $7^{\text {th }}$. The commentary questions the constancy of emotion conveyed by a single chord in its different manifestations, and the extent to which it can afford perception of a complex emotion such as nostalgia.
\end{abstract}

Submitted 2016 February 3; accepted 2016 March 7.

KEYWORDS: nostalgia, emotion, analysis, history, psychology, aesthetics.

LAHDELMA and Eerola's rich article on nostalgia (Lahdelma \& Eerola, 2015) makes a very interesting claim that this emotion can be conveyed by a single chord: the major $7^{\text {th }}$ in its various inversions. According to the authors, nostalgia is a mixed emotion, blending positive and negative valence: i.e., the pleasure of a recalled happy emotion, combined with a painful longing for that emotion. They claim that a major $7^{\text {th }}$ chord conveys this mixed emotion because it combines the positive valence of a major triad with the negative valence of a major $7^{\text {th }}$ or minor $2^{\text {nd }}$ dissonance. The inclination of the dissonant interval to resolve to a triad tone (a tonic or the third degree) is expressive of the yearning or longing associated with nostalgia.

Now, although this idea is fairly arresting, it seems to be counter-intuitive on two grounds. The first issue is the authors' identification of semi-tonal 'yearning' with the emotion of nostalgia. Many music theorists have explored the 'forces' which impel one note to resolve to another (e.g. Larson, 2012; Lerdahl, 2001); however, it is arguable that these processes of tension and resolution are much more generic and fundamental than can be captured by a single emotional category. In other words, tension is a dimension, whereas nostalgia is a category. Dressed in different idioms, tension can project very different emotions such as rising panic or escalating erotic passion. What determines the emotion is the collateral parameters of tempo, texture, dynamics, and articulation through which tension is elaborated. I wonder if Lahdelma and Eerola's subjects would have heard 'nostalgia' if the $7^{\text {th }}$ chords were performed loudly and staccato.

The second issue is whether an emotion as complex as nostalgia can really be captured by a single chord. In referencing works such as the Adagietto from Mahler's Fifth Symphony, the authors are implicitly admitting that the object of their reference isn't a chord so much as an appoggiatura - such as the two-note sighing motive, E-F, at the third bar of the movement. Historically (see Monelle, 2000), appoggiaturas have been recognized figures of sadness and nostalgia in music from Monteverdi to Adèle. It is worth emphasizing that the prototype of musical nostalgia par excellence, Gluck's aria 'Que faro senza Euridice', from his opera Orfeo ed Euridice, conveys this emotion through emphatic appoggiaturas rather than major $7^{\text {th }}$ chords, most characteristically on 1-7 scale-steps, with the 1 suspended against a dominant $7^{\text {th }}$ chord (Lahdelma and Eerola expressly deny that dominant 7ths express nostalgia). On the one hand, in its mixture of happiness and pain, Gluck's aria bears out the authors' analysis of nostalgia as a blended emotion. On the other hand, Gluck creates this effect by saturating a lyrical, major-mode harmonic framework with the acute dissonances of pervasive 1-7 and 4-3 appoggiaturas. This suggests that we can flip Lahdelma and Eerola's argument on its head. It is not that a major $7^{\text {th }}$ triad encapsulates a feeling of nostalgia; rather, only a major $7^{\text {th }}$ projects an appoggiatura against a tonic triad. In short, the chord is an exemplar of a general idiom: major 7ths presuppose appoggiaturas, but appoggiaturas don't require major 7ths. Gluck's example can be multiplied a hundred-fold in my mind with cases of Mozart which sound nostalgic but don't have any $7^{\text {th }}$ chords.

Nostalgia is a very complex emotion because it engages deep questions of history and temporality. The immediate appeal of Lahdelma and Eerola's article is the promise of a short-cut through the thickets of this emotion. It is a good try, but no cigar. 


\section{ACKNOWLEDGEMENTS}

This article was copyedited by Scott Bannister and layout edited by Diana Kayser.

\section{REFERENCES}

Lahdelma, I., and Eerola, T. (2015). Theoretical Proposals on How Vertical Harmony May Convey Nostalgia and Longing in Music. Empirical Musicology Review, 10, 245-263. https://doi.org/10.18061/emr.v10i3.4534

Larson, S. (2012). Musical Forces: Motion, Metaphor, and Meaning in Music. Indiana: Indiana University Press.

Lerdahl, F. (2001). Tonal Pitch Space. New York: Oxford University Press.

Monelle, R. (2000). The Sense of Music. New Jersey: Princeton University Press. 